\section{Author's Accepted Manuscript}

Tomographic measurement of liquid hold up and effective interfacial area distributions in a column packed with high performance structured packings

S. Aferka, A. Viva, E. Brunazzi, P. Marchot, M. Crine, D. Toye

PII: S0009-2509(11)00032-7

DOI: doi:10.1016/j.ces.2011.01.022

Reference: CES 9523

To appear in: $\quad$ Chemical Engineering Science

Received date: $\quad 8$ October 2010

Revised date: $\quad 9$ January 2011

Accepted date: 11 January 2011

\section{CHEMICAL} ENGINEERING SCIENCE

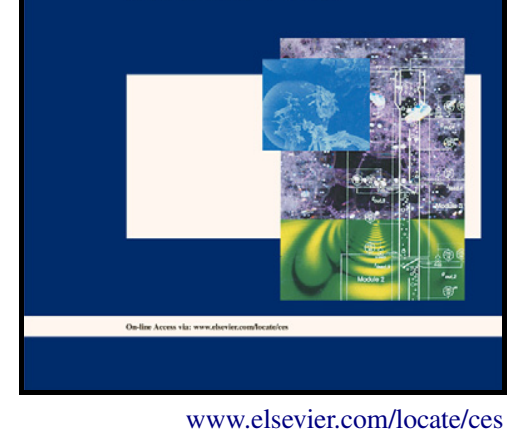

Cite this article as: S. Aferka, A. Viva, E. Brunazzi, P. Marchot, M. Crine and D. Toye, Tomographic measurement of liquid hold up and effective interfacial area distributions in a column packed with high performance structured packings, Chemical Engineering Science, doi:10.1016/j.ces.2011.01.022

This is a PDF file of an unedited manuscript that has been accepted for publication. As a service to our customers we are providing this early version of the manuscript. The manuscript will undergo copyediting, typesetting, and review of the resulting galley proof before it is published in its final citable form. Please note that during the production process errors may be discovered which could affect the content, and all legal disclaimers that apply to the journal pertain. 


\title{
Tomographic measurement of liquid hold up and effective interfacial area distributions in a column packed with high performance structured packings
}

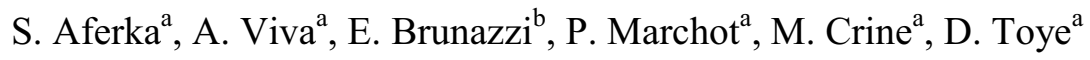 \\ ${ }^{a}$ Laboratory of Chemical Engineering (LGC), University of Liège, Sart-Tilman, B6, B4000 Liège, Belgium \\ ${ }^{\mathrm{b}}$ Department of Chemical Engineering (DICCISM), University of Pisa, 56126 Pisa, Italy
}

Keywords: $\quad$ X-ray tomography, Packed columns, High performance structured packings, Liquid
Hold up distribution, Liquid maldistribution, Effective interfacial area

\begin{abstract}
In this paper, we report on the use of a high energy and high resolution X-ray tomograph to visualize and quantify the distribution of liquid hold up and of gas-liquid interfacial area in a $0.1 \mathrm{~m}$ diameter column filled with MellapakPlus 752.Y packing elements. A standard airwater system at room temperature and atmospheric pressure was used. Tomographic measurements have been carried out in a large number of packing cross sections situated at different heights between the top and the bottom of the packed column, giving access to the evolution of axial profiles of liquid hold up and of gas-liquid interfacial area as a function of the operating conditions. Gas-liquid interfacial area values were also measured by a chemical method $\left(\mathrm{CO}_{2}\right.$ absorption from air into a caustic solution). For the first time, a whole set of gas-liquid interfacial area values evaluated from tomographic images are interestingly compared with values measured by a chemical method. A comparison is also presented with literature models.
\end{abstract}




\section{Introduction}

Metal structured packings are efficient and widely used in vapour-liquid contacting devices (distillation, reactive distillation columns, absorption). In fact, their high void fraction lead to very low pressure drop values and thus to high capacities, whereas their high surface areas lead to high separation efficiencies. A lot of work has been done, mostly in the industrial world, to improve the performance of distillation columns (Adler et al., 2000; Olujic et al., 2003; Schmit and Eldridge, 2004). In particular, a considerable research effort has been devoted to the improvement of structured packing design in order to increase their capacity as well as their separation efficiency (Olujic et al., 2000, 2003, 2007; Billingham et al., 1999; Bender et al., 2003).

In this paper, we focused on MellapakPlus packings and more specifically on the MellapakPlus 752.Y type. This family of "high performance" packing belongs to one of the most recent generations of structured packings manufactured by Sulzer Chemtech. They were developed in 1999 from both experiments and computational fluid dynamics (CFD) on basis of traditional Mellapak (Spiegel et al., 2003). The modified bottom and top ends of each packing layer allows avoiding premature flooding occurring at the junction between two structured packing elements. Compared to conventional Mellapak with similar specific surface area, the pressure drop is lower and the capacity is higher (Brunazzi et al. 2002, Olujic et al. 2009).

However, to fully take advantage of these potentialities requires a better understanding of complex multiphase flow phenomena occurring in structured packed bed. Of particular interest for the improvement of predictive performance models, based on a description of vapour-liquid flow in packed columns is the quantification of global values of liquid hold up 
and of effective mass transfer area, as well as the spatial distributions of these quantities. Gaining a more thorough understanding of the local scale flow in packed columns will allow for the development of more accurate predictive models. Hydrodynamic quantities such as liquid hold up and gas-liquid interfacial area have thus to be measured at a very small scale. X-ray tomography has been shown to be an efficient non-intrusive tool to see inside and to adequately image the liquid and vapour flow distribution in packed columns (Schmit et al., 2001, 2004; Schmit and Eldridge, 2004; Green et al., 2007; Toye et al., 2005; Aferka et al., 2007, 2010a, 2010b; Viva et al. 2010). Green et al. (2007) used X-ray CT to determine the effective wetted area and local liquid hold up for an air-water contactor containing structured packings, and especially traditional Mellapak 250.Y. However, these authors evaluated the effective wetted area for only one liquid flow rate and thus, they do not provide any information on the evolution of effective wetted area as a function of operating conditions. Aferka et al. (2010a) proposed an original image processing methodology to determine the interfacial gas-liquid area from tomographic images of complex catalytic packings.

In this paper, a high energy and high resolution X-ray tomograph is used to measure the evolution of axial profiles of liquid hold up and of gas-liquid interfacial area as a function of the operating conditions. Averaging these distributions gives access to global, bed scale values which may be compared, for validation, to global values measured by traditional methods, as well as to values predicted by correlations available in the literature.

\section{Experimental set up}

The column used in this study is $4 \mathrm{~m}$ high and has an inner diameter equal to $0.1 \mathrm{~m}$. It is made of transparent PVC. The packed bed (0.8 m high) is constituted by four MellapakPlus 752.Y 
elements rotated by $90^{\circ}$ with respect to each other. MellapakPlus $752 . \mathrm{Y}$ is a high capacity structured packing, manufactured by Sulzer Chemtech, CH. Packing elements are $0.2 \mathrm{~m}$ high, their diameter equal $0.10 \mathrm{~m}$. They are made of the vertical juxtaposition of $0.1 \mathrm{~mm}$ thick stainless steel corrugated sheets that are embossed and perforated with $4 \mathrm{~mm}$ holes (Figure1). The packing element geometric characteristics are presented in table 1. An air-water system was used as working fluids. The superficial velocities of the liquid and gas phases ranged between 4.62 and $23.10 \mathrm{~m}^{3} /\left(\mathrm{m}^{2} \mathrm{~h}\right)$ and 0 and $2 \mathrm{~m} / \mathrm{s}$, respectively. A multiple point source distributor (4000 drip points $/ \mathrm{m}^{2}$ ) was used to feed the liquid at the top of the column. To ensure an even initial liquid distribution in the structured packed bed, a $0.5 \mathrm{~m}$ high layer of random packings (plastic Pall rings, 1 inch diam.) is installed between the liquid distributor and the top of the structured packing.

\section{Figure 1}

Table 1

\section{Experimental methods}

\subsection{X-ray Tomography}

The X-ray CT facility is a high energy $(420 \mathrm{kV}) \mathrm{X}$-ray tomograph equipped with a fan beam X-ray source and with a 1280 photodiodes linear detector which are both fixed on an arm able to translate vertically along the scanned object height (Figure 2). Scanned objects are put on a rotating plate which may perform a complete revolution around a vertical axis. There are 2560 angular positions for a complete turn $\left(360^{\circ}\right)$ for each scan. Objects with diameters up to 0.45 $\mathrm{m}$ diameter and with height up to $3.8 \mathrm{~m}$ may be analyzed with a spatial resolution equal to $0.37 \mathrm{~mm}$. More details are provided in Toye et al. (2005). This X-ray CT may work in radiographic mode as well as in tomographic mode. When used in radiographic mode, the 
rotating plate of the scanner is deactivated and the scanned object remains fixed. 2D radiographic images correspond to X-ray attenuation horizontal profiles measured at different heights by vertically translating the arm. In tomographic mode, the vertical arm remains fixed while the scanned object is rotated in order to get attenuation profiles for all angular positions. From these attenuation data, one may obtain the image of the column cross-section corresponding to the vertical position of the arm. Images of cross sections situated at different heights may be obtained by repeating the measurement procedure for different positions of the arm supporting the X-ray source and the detector. X-ray tomography is thus a time consuming measurement technique as, for each operating condition, a large number of cross section images (70 in the present work) have to be reconstructed to get information on phase distributions relative to the whole bed.

Figure 3 shows a radiographic image (radiogram) of the whole packed bed obtained with the X-ray CT used in radiographic mode. On this radiogram, one may see four MellapakPlus 752.Y (M1, M2, M3, M4) and a $0.5 \mathrm{~m}$ high layer of Pall rings. Above, the liquid distributor is visible. The round patch on the column wall corresponds to a pressure measurement point.

\section{Figure 2}

\section{Figure 3}

Tomographic measurements have been performed in packing cross sections situated at different heights between the top and the bottom of the packed column with, as well as without, liquid and gas flow. As explained in more details in Toye et al. (2005), reconstructed images of these cross sections are obtained by a classical linear back projection algorithm adapted to the fan beam geometry implemented in the Fourier domain. To obtain the liquid contribution, the projection data obtained on the dry column are subtracted, before 
reconstruction, from those obtained at the same height on the irrigated column. The resulting projection data are then used to obtain liquid distribution image.

In order to eliminate the background noise affecting reconstructed images, various numerical treatments are applied to raw images (Aferka et al., 2007). Reconstructed sections are squares of 499x 499 pixels and the spatial resolution in horizontal planes is around $0.36 \mathrm{~mm}$.

\subsection{Global methods used in this study}

\section{Draining method}

The draining method is classically used to obtain dynamic liquid hold up values relative to the whole packed bed, i.e. global values. It consists in the following steps. First, a steady-state liquid flow is reached in the packed bed. Next, the liquid and gas feed are stopped simultaneously and the liquid draining by gravity is collected at the bottom of the packed bed. The dynamic liquid hold up, which corresponds to liquid retained inside the packed bed under operation, is then computed as the ratio between the volume of collected liquid and the total volume of the packed bed.

In the present study we used the experimental facility described by Viva and Brunazzi (2009) in their investigation on catalytic packing. The $0.1 \mathrm{~m}$ internal diameter column was filled with the four MellapakPlus 752.Y packing elements. The liquid was fed by means of a multiple point distributor (4000 drip points $\left./ \mathrm{m}^{2}\right)$ and liquid loads up to $26 \mathrm{~m}^{3} /\left(\mathrm{m}^{2} \mathrm{~h}\right)$ were tested. The results refer to draining times of $15 \mathrm{~min}$.

The main advantages of the draining method are its simplicity and its speed as values of dynamic liquid hold up are obtained immediately without requiring any complex equipment. However, due to its global nature, it does not give access to any information on the local scale phenomena occurring within the packed bed. 


\section{Chemical method (CO2 absorption in a caustic solution)}

Chemical absorption rate data in the fast-reaction regime is frequently employed to determine effective gas-liquid interfacial area in packed columns (Danckwerts, 1970, Charpentier, 1976).

Among the large variety of the two-fluid systems, the absorption of $\mathrm{CO} 2$ into $\mathrm{NaOH}$ solution is especially proper (Kolev et al. 2006, Rejl et al. 2009). CO2 reacts in the liquid phase with $\mathrm{NaOH}$ and forms bicarbonate and carbonate. The reaction is of second order and the formation of the bicarbonate ion is the limiting reaction. The value of its equilibrium constant at ambient temperature is large enough to allow considering the reaction as practically irreversible. The kinetics of the system has been extensively studied and characterised (Pohorecki and Moniuk, 1988, Kolev et al. 2006).

Weimer and Schaber (1996) have extensively investigated how the test conditions must be chosen in order to operate in the desired fast reaction of pseudo-first order condition. They found that using air (i.e. with only some 380 ppmv CO2), instead of a CO2 enriched gas stream, has no effect on the reaction regime, and that the method is preferable because this way, the use of chemicals is significantly reduced and more importantly caustic and carbonate concentrations change very slowly. The gas side resistance is limited by operating at high gas velocities (1-2 m/s). Effective gas-liquid interfacial area measurements using air and 0.1-1 molar $\mathrm{NaOH}$ solution have been recently reported by Tsai et al. (2010), Alix et al. (2010), Duss et al. (2010) to characterise structured packing.

In this paper we used the same method to determine the effective interfacial area of MellapakPlus 752.Y.

The experimental setup for this study is located at the Department of Chemical Engineering of the University of Pisa. The column has an internal diameter of $0.10 \mathrm{~m}$ and is $2 \mathrm{~m} \mathrm{high}$. It is 
made of transparent plexiglass. The packed bed is constituted by seven MellapakPlus 752.Y elements, rotated by $90^{\circ}$ with respect to each other. The column was operated at atmospheric pressure and room temperature.

Air is supplied by a compressor, pre-humidified and fed at the bottom of the column. Gas velocities were comprised between 0.6 and $1.4 \mathrm{~m} / \mathrm{s}$. A multiple point source distributor was used to feed the liquid at the top of the column. The liquid was a 0.3 molar sodium hydroxide solution recirculating at liquid loads ranging from 5 to $27 \mathrm{~m}^{3} /\left(\mathrm{m}^{2} \mathrm{~h}\right)$. The column is attached to a 500 litre capacity storage which ensures that the caustic solution concentration is constant during the tests. Nevertheless, liquid samples both at the inlet and the outlet of the packing were taken during the runs. The concentrations of hydroxides and carbonates in the liquid samples were determined by titration with $\mathrm{HCl}$. Also temperature of gas and liquid were accurately measured during the runs. Ionic strength of the solution, hydroxides concentration and temperatures have a significant impact when evaluating the interfacial area (Duss at al., 2010) this is the reason why they need to be accurately measured and monitored.

Gas samples were withdrawn at different locations along the column. Besides monitoring inlet and outlet air streams, samplings were taken directly from the packed portion of the column to avoid end effects (Rejl et al. 2009). The $\mathrm{CO}_{2}$ concentration was measured by an infrared gas analyzer (Ecocontrol AD 30), calibrated with $\mathrm{N}_{2}$ for zero point and $590 \mathrm{ppm} \mathrm{CO}_{2} /$ air span gas. The 4-20mA signal was recorded continuously on a data logger and stored on a PC.

To evaluate the effective interfacial area from the resulting experimental data we used the physico-chemical property values and reaction kinetic constants published by Pohorecki and Moniuk (1988).

Similarly to Alix et al. (2010), one dimensional and stationary plug flows of gas and liquid were assumed within the packed bed as well as isobar and isotherm operating conditions. The material balance on a differential section of the column was integrated over the packed bed to 
calculate the composition profiles along the column. The effective interfacial area was assumed to be constant. It is the only parameter to adjust in order to fit the measured $\mathrm{CO} 2$ profile and meet the sodium hydroxide concentration in the liquid bulk measured at the column inlet and outlet. The gas side resistance was estimated to account for $4-7 \%$ of the overall mass transfer resistance, with the gas-side mass transfer coefficient calculated from the correlation of Brunazzi et al. (1995).

\section{Results and discussions}

\subsection{Images of dry packings}

In order to get images of packing without any residual liquid, packing elements were dried in oven at $100^{\circ} \mathrm{C}$ for 10 hours before tomographic measurements. Figure 4 illustrates a reconstructed cross section of a MellapakPlus 752.Y packing element, scanned at a height situated near the top of the element (red line on the picture). Column wall (1), corrugated sheet (2), wall wiper (3), perforations (4) and embossing are clearly visible.

\section{Figure 4}

\subsection{Geometrical parameters computed from tomographic images}

In order to get quantitative information from tomographic images, some numerical treatments are required (thresholding, skeletisation, normalisation ...). Figures $5 \mathrm{a}$ and $5 \mathrm{~b}$ show the axial profiles of porosity and of geometric specific surface area in the packed bed made of four MellapakPlus 752.Y. The porosity and specific surface area are estimated on 70 sections distributed along the bed height. The vertical lines correspond to nominal values provided by 
the packing manufacturer and listed in Table 1. Logically, cross sections surrounded by wall wipers are characterised by lower porosity values and by higher specific surface area. Porosity and specific surface area values relative to the whole packed bed, i.e. volumetric or global values, can be estimated by averaging local values relative to the 70 cross sections.

The global value of porosity equals 0.971 if all cross sections are taken into account. A higher value, equal to 0.975 is obtained if only cross sections without wall wipers are considered. This last value matches the nominal porosity provided by the manufacturer, which does take the contribution of wall wipers into account. Green et al. (2007) also observed this difference for traditional Mellapak 250.Y.

The axial profile of geometric specific surface area is quite non uniform, due to the presence of wall wipers which increase the local value of specific surface area and of perforations in the corrugated sheets of packings which decrease the local specific surface area. A global value equal to $454 \mathrm{~m}^{2} / \mathrm{m}^{3}$ is obtained if all the 70 reconstructed cross section are considered, while it only equals $411 \mathrm{~m}^{2} / \mathrm{m}^{3}$ if cross sections surrounded by a wall wiper are not considered. If the nominal value provided by the packing manufacturer is corrected to account for the impact of perforations $(-10 \%)$, of wall wipers $(+9 \%)$ and of the actual diameter of the packing (-10\%) (Aferka et al., 2010a), a value of $450 \mathrm{~m}^{2} / \mathrm{m}^{3}$ is obtained, which is in good agreement with the result obtained from the global set of tomographic measurements.

\section{Figure 5}

\subsection{Images of irrigated packings}

In order to get a good wetting of the packing in irrigated conditions, the packed column is first completely filled with water. Then, before each measurement, the column is again pre-wetted with a high liquid flow rate. To analyse the influence of a counter-current gas flow on liquid distribution, air has been injected at the bottom of the structured packed bed. 
Measurements are performed using liquid superficial velocities ranging between 0 and 23.10 $\mathrm{m}^{3} /\left(\mathrm{m}^{2} \mathrm{~h}\right)$ and with gas superficial velocities ranging between 0 and $2 \mathrm{~m} / \mathrm{s}$, which correspond to $F_{\mathrm{G}}$ factors ranging between 0 and $2.2 \mathrm{~m} / \mathrm{s}\left(\mathrm{kg} / \mathrm{m}^{3}\right)^{0.5}$.

Figure 6 presents images of irrigated packing corresponding to cross sections situated at different heights in the column. In this figure, axes are given in pixels. One pixel has a length equal to $0.36 \mathrm{~mm}$. On all images, the liquid superficial velocity equals $23.10 \mathrm{~m}^{3} / \mathrm{m}^{2} . \mathrm{h}$ and there is no gas flow.

To obtain these images, we proceed as follows. First, dry packing images are recorded, reconstructed and thresholded, leading to the gray part of the images. Then, corresponding irrigated cross sections are reconstructed and thresholded, leading to the blue part of the images. Finally, gray and blue parts are superimposed. Qualitatively, we notice that liquid distribution in cross sections is almost uniform, even if thicker liquid zones are observed near the contact points between adjacent corrugated sheets. Liquid has adopted the same shape as corrugated sheets indicating that the film flow predominates. One can also observe that wall flow is limited which indicates that wall wipers efficiently push the liquid back towards the inside of the bed (Figures $6 a, 6 c, 6 d)$.

\section{Figure 6}

\subsection{Liquid hold up measurement by X-ray CT}

$\mathrm{X}$-ray CT gives access to static and total liquid hold up contributions:

- the static liquid hold up is the liquid remaining in the packed bed after drainage. It corresponds to liquid trapped at contact points between adjacent corrugated sheets or to liquid drops remaining on the sheets after the liquid films covering these sheets are broken by drainage; 
- the total liquid hold up is the liquid effectively present in the packing during operation. On reconstructed images, the pixel size is larger than the size of individual liquid flow structures (films, rivulets, droplets). To take this partial volume effect into account and get accurate quantitative values for liquid hold up, a normalization factor corresponding to a pixel completely filled with liquid has to be determined. To this end, the column is totally filled with water and tomographic images of liquid distribution are recorded in a large number of cross sections. The normalization factor for liquid is then determined a posteriori, in such way that the total liquid hold up in the completely flooded bed equals to its porosity, previously measured on dry packing images.

\section{Static hold up}

For the determination of static liquid hold up, the column is first totally filled with liquid, and then drained during 24 hours. Figure 7 shows images of static liquid hold up distributions measured in cross sections situated near the bottom (7a) and near the top (7b) of a MellapakPlus 752.Y packing element, respectively. The blue part of the images corresponds to liquid contribution and the gray part to the solid phase. As expected, the liquid is mainly retained at the contact points between adjacent corrugated sheets and in the internal porosity of wall wiper. On figure 8 , the static hold up obtained by X-ray tomography at various heights in the four MellapakPlus 752.Y elements is plotted as a function of elevation from the bottom of the structured packed bed. All static liquid hold up values are very low, ranging between 1 and $2 \%$, depending on the number of the contact points between adjacent corrugated sheets and the presence of wall wiper. Peaks correspond to cross-sections at the transition between packing elements. In fact, in this zone, there are more contact points due to the contact between packing elements.

\section{Figure 7}




\section{Figure 8}

\section{Liquid flow without gas}

Figure 9 presents axial profiles of total liquid hold up for different liquid superficial velocities as a function of elevation from the bottom of the structured packed bed. There is no gas flow. As expected, the total liquid hold up increases with liquid velocity. Liquid hold up values are not constant along the packed bed height. Minimum values are observed at junctions between elements of MellapakPlus 752.Y. In these cross sections, the packing specific surface area decreases and liquid flows in the form of small rivulets.

\section{Figure 9}

\section{Counter-current gas-liquid flow}

Figure 10 shows the influence of a counter current gas flow on liquid hold up in the column. It presents global values of the total liquid hold up as a function of gas velocity for different liquid velocities. These global values are obtained by averaging local hold up values relative to different cross sections distributed along the whole packed bed height. As expected, liquid hold up increases with liquid and gas velocity. The gas flow has a less pronounced influence, particularly at low liquid velocity, far from the loading point. The influence of the $\mathrm{F}_{\mathrm{G}}$ factor is however more clearly observed at higher liquid velocities, when approaching the loading point. Experimentally flooding points occurred at $F_{G}$ around 2, 2.5 and above $3.5 \mathrm{~m} / \mathrm{s}$ $\left(\mathrm{kg} / \mathrm{m}^{3}\right)^{0.5}$ for the liquid loads of $23.1,12.7$ and $4.62 \mathrm{~m}^{3} /\left(\mathrm{m}^{2} \mathrm{~h}\right)$, respectively. 


\section{Figure 10}

\section{Comparison with other data}

In order to assess the reliability of global liquid hold up values measured from tomographic images, they are compared to other experimental values, as well as with values predicted using proven correlations available in literature.

Figure 11 compares two sets of experimental values of global liquid hold up obtained by tomography and by the draining technique by Viva (2008) on exactly similar packed beds $(0.1$ $\mathrm{m}$ inner diameter column packed with 4 MellapakPlus 752.Y elements). The data from Viva include a $1.3 \%$ static hold up contribution, and for each liquid load are within $\pm 3-4 \%$ of the mean value. A very good agreement is observed.

\section{Figure 11}

Figure 12 compares X-ray tomography values of total liquid hold up with values calculated with several correlations available in the literature. A fairly good agreement is observed with predictions of correlations proposed by Suess and Spiegel (1992). In fact, Suess and Spiegel measured liquid hold up for various types of Mellapak packings (i.e. 250.X, 250.Y, and 500.Y). The $\mathrm{X}$ and $\mathrm{Y}$ version differ in the corrugation angle with respect to the horizontal axis, which is of $60^{\circ}$ for the $\mathrm{X}$ version and of $45^{\circ}$ for the $\mathrm{Y}$ version. They have shown that the corrugation angle has a negligible effect on the liquid hold up whereas the specific surface area affects significantly the liquid hold up. The MellapakPlus 752.Y is the high performance version of the Mellapak 500.Y: the two packings have similar specific surface area, while the corrugation angle differs of just $3^{\circ}$ in the main portion of the packing. Hence it can be supposed that the liquid hold up correlation given for Mellapak 500.Y is reasonable for evaluating the liquid hold up of the MellapakPlus 752.Y. The last version of the software Sulpak developed by Sulzer Chemtech (Sulcol 2.0.9), which includes MellapakPlus packings, 
calculates the same hold up for the two packings. Moreover, correspondence between experimental data and calculated values using Sulcol was confirmed also by Olujic et al. (2007).

\section{Figure 12}

\subsection{Gas-Liquid interfacial area}

\subsubsection{From tomographic images}

The gas-liquid interfacial area is measured on tomographic images using an original method developed at the Chemical Engineering Laboratory of the University of Liège. It is based on the counting of the number of liquid pixels which are in contact with the gas phase. It is described in more details in Aferka et al. (2010a).

Figure 13 shows axial profiles of gas-liquid interfacial area measured for different liquid velocities as a function of elevation from the bottom of the structured packed bed. These profiles show that the gas-liquid interfacial area is not constant over the whole packed bed height. A comparison of figures $6 \mathrm{~b}$ and 13 shows that, for all liquid loads, the interfacial surface area in a cross section is strongly correlated to the packing specific area in this cross section. So, logically, comments relative to the distribution of specific surface area remain valid for the distribution of gas-liquid interfacial area. Maximum values of interfacial area are measured in cross sections surrounded by a wall wiper and minimum values are observed in cross sections not surrounded by a wall wiper and where packing corrugated sheets are perforated.

\section{Figure 13}

Global values of gas-liquid interfacial area may be computed by averaging local values relative to cross sections distributed over the whole column height. They range between 255 and $454 \mathrm{~m}^{2} / \mathrm{m}^{3}$, depending on the operating conditions. The last value, $454 \mathrm{~m}^{2} / \mathrm{m}^{3}$, is measured 
for the highest liquid flowrate. It equals the packing specific surface area value computed from tomographic images, indicating that, in these conditions, the whole packing surface is wetted by the liquid flow.

The quality of contact between gas and liquid may interestingly be represented by the ratio $\mathrm{a}_{\mathrm{GL}} / \mathrm{a}_{\mathrm{SP}}$. Figure 14 shows the effect of gas on the profile of the fractional area $\left(\mathrm{a}_{\mathrm{GL}} / \mathrm{a}_{\mathrm{SP}}\right)$ over the whole packed bed height for a liquid flow rate equal to $12.7 \mathrm{~m}^{3} /\left(\mathrm{m}^{2} \mathrm{~h}\right)$ and for three values of the $\mathrm{F}_{\mathrm{G}}$ factor. The mean value of the ratio $\mathrm{a}_{\mathrm{GL}} / \mathrm{a}_{\mathrm{SP}}$ calculated for these operating conditions are respectively equal to $0.71,0.76$ and $0.82 \mathrm{~m}^{2} / \mathrm{m}^{3}$. Logically, for a given liquid flow rate, the interfacial area increases with gas flow rates.

\section{Figure 14}

\subsubsection{Comparisons with other data}

Global values computed from tomographic images are compared with other data in order to assess the reliability of this new method. Tomographic results are first compared to experimental data obtained by a chemical method (carbon dioxide absorption into an aqueous solution of sodium hydroxide). The measured global area are within $\pm 3 \%$ of the mean value for each liquid load. As shown on figure 15, a surprisingly good agreement is found between values obtained by using these experimental techniques. At first sight, the agreement between the two techniques was not obvious as the interfacial area measured by absorption technique corresponds to the reactive area which is not necessarily equal to the geometrical interfacial area measured from tomographic images.

\section{Figure 15}

Figure 16 compares tomographic results (for $\mathrm{F}_{\mathrm{G}}=0.5 \mathrm{~m} / \mathrm{s}\left(\mathrm{kg} / \mathrm{m}^{3}\right)^{0.5}$ ) with values of gas-liquid interfacial area calculated with correlations available in the literature. The agreement with predicted values is good for the correlation proposed by Tsai et al. (2010). Larger deviations are observed if tomographic results are compared to the correlations suggested by Behrens 
(2006) and by Rocha et al. (1996) which both predict significantly lower values of $\mathrm{a}_{\mathrm{GL}}$. This behaviour can be explained as partly due to a reliance on distillation data (Tsai et al. 2010), which generally consists of systems with lower surface tension compared to aqueous systems. The figure shows also the values predicted by using the correlation suggested by de Brito et al. (1994) developed from experiments with the $\mathrm{CO} 2 / \mathrm{NaOH}$ system on Mellapak type packings. As clearly discussed recently by Rejl et al. (2009), the suspicious high wetted area evaluated by the correlation from de Brito et al. is due to the wrong set of physico-chemical property values and reaction kinetic constants used by the authors to evaluate effective area from $\mathrm{CO} 2$ transfer rate.

\section{Figure 16}

\section{Conclusions}

High energy, high resolution tomography has been successfully applied to visualize liquid distribution in a structured packed bed as a function of operating conditions. An original image processing methodology was used to analyse tomographic images and to compute local and global values of liquid hold up and of gas-liquid interfacial area.

For the first time, a whole set of tomographic values of global liquid hold up and of gas-liquid interfacial area, relative to complete range of operating conditions, was successfully compared to previously published liquid hold up data and to new experimental values of interfacial area. The very good agreement observed between all experimental data as well as with literature correlations allows assessing the reliability of this new measurement technique.

Moreover, $\mathrm{x}$-ray tomography gives access to the liquid distribution down to a very local scale. The analysis of cross section images show that liquid hold up and gas-liquid interfacial area are far from constant in the whole packed bed as generally assumed in hydrodynamic models. Their values as well as their spatial distributions vary strongly from one cross section to the 
next one along the packing height. The analysis of liquid distribution in packing cross sections reveals a liquid accumulation at contact points between adjacent corrugated sheets. Liquid also seems to accumulate preferentially in cross sections surrounded by a wall wiper. All these local accumulations of liquid may lead to premature flooding of the packed bed.

All these information relative to the local scale distribution of liquid and of hydrodynamic quantities such as liquid hold up and gas-liquid interfacial area are invaluable to improve the description of hydrodynamics in rate based performance models.

\section{Acknowledgments}

The authors wish to thank Sulzer Chemtech for supplying the MellapakPlus 752.Y packing elements. The assistance of Francesco Burattini is gratefully acknowledged.

\section{References}

Adler, S., Beaver, E., Bryan, P., Robinson, S., Watson, J., 2000. Vision 2020- Separations Roadmap, American Institute of Chemical Engineers, New York.

Aferka, S., Crine, M., Saroha, A.K., Toye, D., Marchot, P., 2007. In situ measurements of the static liquid hold up in Katapak-SP12 packed column using X-ray tomography. Chemical Engineering Science 62, 6076-6080.

Aferka, S., Marchot, P., Crine, M., Toye, D., 2010a. Interfacial area measurement in a catalytic distillation packing using high energy X-ray CT. Chemical Engineering Science 65, $511-516$ 
Aferka, S., Viva, A., Brunazzi, E., Marchot, P., Crine, M., Toye, D., 2010b. Liquid load point measurement in a reactive distillation packing by x-ray tomography. Canadian Journal of Chemical Engineering 88, 611-617.

Alix, P., Raynal, L., Abbe, F., Meyer, M., Prevost, M., Rouzineau, D., 2010. Mass transfer and hydrodynamic characteristics of a new carbon packing: application to $\mathrm{CO} 2$ postcombustion capture. Chemical Engineering Research Design, DOI: 10.1016/j.cherd.2010.09.023.

Behrens, M., 2006. Hydrodynamics and mass transfer performance of modular catalytic structured packing, Ph.D. Thesis, TU Delft.

Bender, P., Moll, A., 2003. Modifications to structured packings to increase their capacity. Transactions of the IChemE: Chemical Engineering Research and Design 81, 58.

Billet, R., Schultes, M., 1993. Predicting mass transfer in packed columns. Chemical Engineering Technology 16, 1-9.

Billingham, J. F., Lockett, M. J., 1999. Development of a new generation of structured packings for distillation. Transactions of the IChemE: Chemical Engineering Research and Design $77,583$.

Brunazzi E., Nardini, G., Paglianti, A., Petarca, L., 1995. Interfacial area of mellapak packing: absorption of 1,1,1-trichloroethane by genosorb 300. Chemical Engineering and Technology, $18,248-255$.

Brunazzi, E., Paglianti, A., Spiegel, L., Tolaini, F., 2002. Hydrodynamics of a gas-liquid column equipped with MellapakPlus packing. Proceedings of the $7^{\text {th }}$ International Conference on Distillation and Absorption, Baden-Baden, DE, P6.17, pp. 1-18.

Charpentier, J.C., 1976. Recent progress in two-phase gas-liquid mass transfer in packed beds. Chemical Engineering Journal 11, 161-181.

Danckwerts, P. Gas-liquid reactions. McGraw Hill, New York, 1970. 
de Brito M., H., von Stockar, U., Menendez Bangerter, A., Bomio, P., Laso, M., 1994. Effective mass-transfer area in a pilot plant column equipped with structured packings and with ceramic rings. Industrial Engineering Chemistry and Research 33, 647-656.

Duss, M., Meierhofer, H., Nutter, D.E., 2001. Effective interfacial area and liquid hold up of Nutter rings at high liquid loads. Chemical Engineering and Technology 24, 716-723.

Duss, M., Menon, A., 2010. Optimized absorber design for post-combustion CCS. Proceedings of the $9^{\text {th }}$ Distillation and Absorption Conference, Eindhoven, The Netherlands, 12-15 September 2010, pp. 109-114.

Green, C.W., Farone, J., Briley, J.K., Eldridge, R.B., Ketcham, A.R., Nigtingale, B., 2007. Novel application of X-ray computed tomography: determination of gas/liquid contact area and liquid hold up in structured packing. Industrial Engineering Chemistry and Research 46, 5734-5753.

Kolev, N., Nakov, S., Ljutzkanov L., Kolev, D., 2006. Effective area of a highly efficient random packing. Chemical Engineering Processing 45, 429-436.

Olujic, Z., Seibert, A.F., Fair, J.R., 2000. Influence of corrugation geometry on the performance of structured packings: an experimental study. Chemical Engineering Processing 39,355 .

Olujic, Z., Frey, G., Jansen, H., Kaibel, B., Rietfort, T. , Zich, E., 2003. Distillation column internals related process intensification developments. Proceedings of the Sixth Italian Conference on Chemical and Process Engineering, June 2003, Pisa (Italy), in Chemical Engineering Transactions, 3, 367-372.

Olujic, Z., Behrens, M., Spiegel, L., 2007. Experimental characterization and modelling of the performance of a large specific area high capacity structured packing. Industrial Engineering Chemistry and Research 46, 883-893. 
Olujic, Z., Jödecke, M., Shilkin, A., Schuch, G., Kaibel, B., 2009. Equipment improvement trends in distillation. Chemical Engineering and Processing: Process intensification 48, 10891104.

Pohorecki, R., Moniuk, W., 1988. Kinetics of reaction between carbon dioxide and hydroxyl ions in aqueous electrolyte solutions. Chemical Engineering Science 43, 1677-1684.

Rejl, J.F., Linek, V., Moucha, T., Valenz, L., 2009. Methods standardization in the measurement of mass-transfer characteristics in packed absorption columns. Chemical Engineering Research and Design 87, 695-704.

Rocha, J. A., Bravo, J. L., Fair, J. R., 1996. Distillation columns containing structured packings: a comprehensive model for their performance. 2. Mass transfer model. Industrial Engineering Chemistry and Research 35, 1660-1667.

Schmit, C.E., Cartmel, D.B., Eldridge, R.B., 2001. The experimental application of X-ray tomography to a vapor-liquid contactor. Chemical Engineering Science 56, 3431-3441.

Schmit, C.E., Eldridge, R.B., 2004. Investigation of X-ray imaging of vapor-liquid contactors. I. Studies involving stationary object and a simple flow system. Chemical Engineering Science 59, 1255-1266.

Schmit, C.E., Perkins, J., Eldridge, R.B., 2004. Investigation of X-ray imaging of vaporliquid contactors. 2. Experiments and simulations of flows in an air-water contactor. Chemical Engineering Science 59, 1267-1283.

Suess, P., Spiegel, L., 1992. Hold-up of mellapak structured packings. Chemical Engineering and Processing 31, 119-124.

Spiegel, L., Meier, W., 2003. Distillation columns with structured packings in the next decade. Transactions of IChemE: Chemical Engineering Research Design 81, 39. 
Toye, D., Crine, M., Marchot, P., 2005. Imaging of liquid distribution in reactive distillation packings with a new high energy X-ray tomograph. Measurement Science Technology 16, 2213-2220.

Tsai, R. E., Seibert, F., Eldridge, R. B., Rochelle, G.T., 2010. A dimensionless model for predicting the mass transfer area of structured packing. A.I.Ch.E. Journal, DOI: 10.1002/aic. 12345 .

Viva, A., 2008. Experimental analysis and modelling of novel catalytic structured packing for reactive separation processes, Ph.D. thesis, University of Pisa.

Viva, A., Brunazzi, E., 2009. The influence of modular structure on the hydrodynamics of catalytic structured packings for reactive separation processes. AIDIC Conference Series, Vol. 9, 345-353. DOI: 10.3303/ ACOS0909040.

Viva, A., Aferka, S., Toye, D., Marchot, P., Crine, M., Brunazzi, E., 2010. Measurement of liquid hold-up in catalytic structured packings: comparison of different experimental techniques. Proceedings of the $9^{\text {th }}$ Distillation and Absorption Conference, Eindhoven, The Netherlands, 12-15 September 2010, pp. 599-604.

Weimer T., Schaber, K., 1996. Ermittlung effektiver Phasengrenzflaechen durch Kohlendioxidiabsorption aus Luft. Chemische Technik 48, 237-288.

\section{Figures legends:}

Figure 1: Photo of the MellapakPlus 752.Y (Top and side view).

Figure 2: X-ray CT device.

Figure 3: Radiogram of the column.

Figure 4: Raw image in grayscale of a cross section of MellapakPlus 752.Y

Figure 5: Profile of porosity and of specific area along the column height for MellapakPlus 752.Y.

Figure 6: Evolution of liquid distribution inside MellapakPlus 752.Y: a) $500 \mathrm{~mm}$, b) $600 \mathrm{~mm}$, c) $700 \mathrm{~mm}$ and d) $800 \mathrm{~mm}$ from the bottom of packed bed for $U L=23.10 \mathrm{~m}^{3} /\left(\mathrm{m}^{2} \mathrm{~h}\right)$ and no gas.

Figure 7: Static liquid hold up in a cross section near the bottom (a) and near the top (b) of the MellapakPlus 752.Y packing.

Figure 8: Static liquid hold up vs. Height in the bed. 
Figure 9: Axial profile of total liquid hold up along the column height for different liquid superficial velocities and with no gas load.

Figure 10: Global values of total liquid hold up for different liquid and gas velocities.

Figure 11: Global liquid hold up as function of liquid velocity.

Figure 12: Comparison between values of liquid hold up obtained from x-ray tomography and correlations available in the literature.

Figure 13: Gas-liquid interfacial area along the column height for different superficial liquid velocity and no gas.

Figure 14: Profile of the ratio $\mathrm{a}_{\mathrm{GL}} / \mathrm{a}_{\mathrm{SP}}$ along the packed bed height for $\mathrm{UL}=12.7 \mathrm{~m}^{3} /\left(\mathrm{m}^{2} \mathrm{~h}\right)$ and for different values of the FG factor.

Figure 15: G/L interfacial area vs liquid load. Comparison between tomographic results (for $\left.\mathrm{FG}=1.3 \mathrm{~m} / \mathrm{s}\left(\mathrm{kg} / \mathrm{m}^{3}\right)^{0.5}\right)$ and data obtained from the chemical method (for $\mathrm{FG}=0.7-1.5 \mathrm{~m} / \mathrm{s}$ $\left.\left(\mathrm{kg} / \mathrm{m}^{3}\right)^{0.5}\right)$.

Figure 16: $\mathrm{G} / \mathrm{L}$ interfacial area vs liquid load. Comparison between tomographic results $(\mathrm{FG}=$ $\left.0.5 \mathrm{~m} / \mathrm{s}\left(\mathrm{kg} / \mathrm{m}^{3}\right)^{0.5}\right)$ and computed values.

\section{Table legend:}

Table 1: MellapakPlus 752.Y geometrical parameters. 

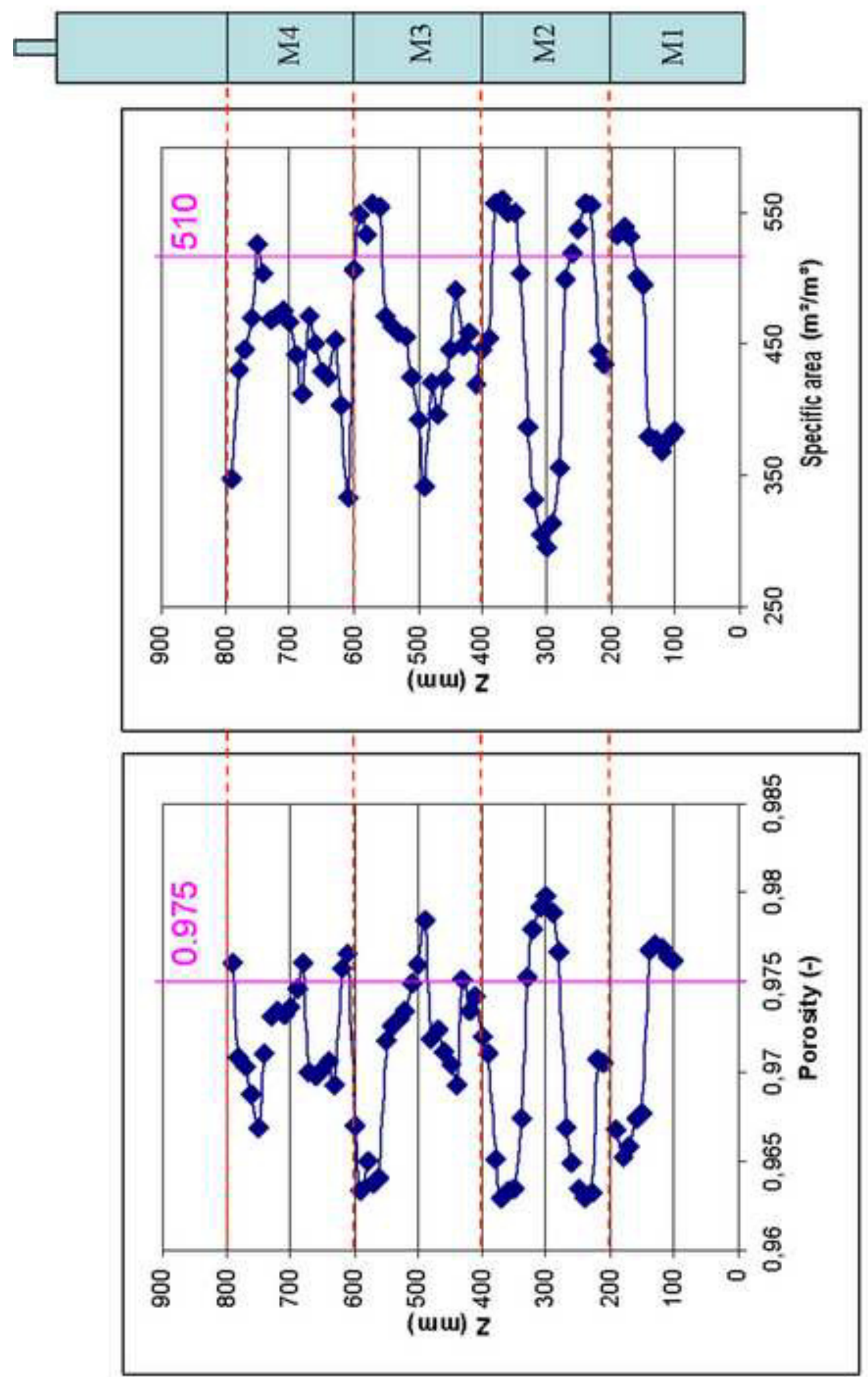


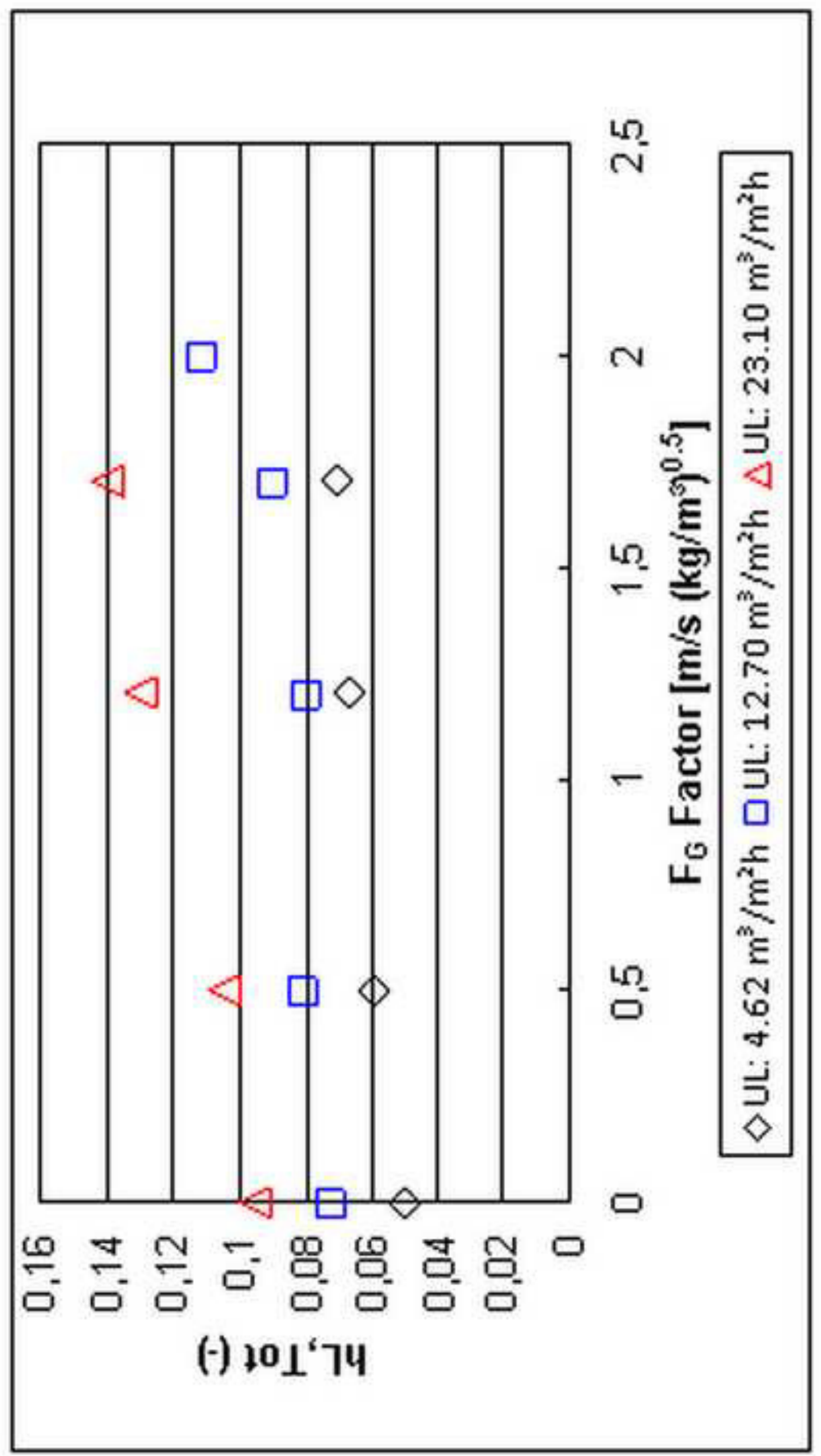

은 


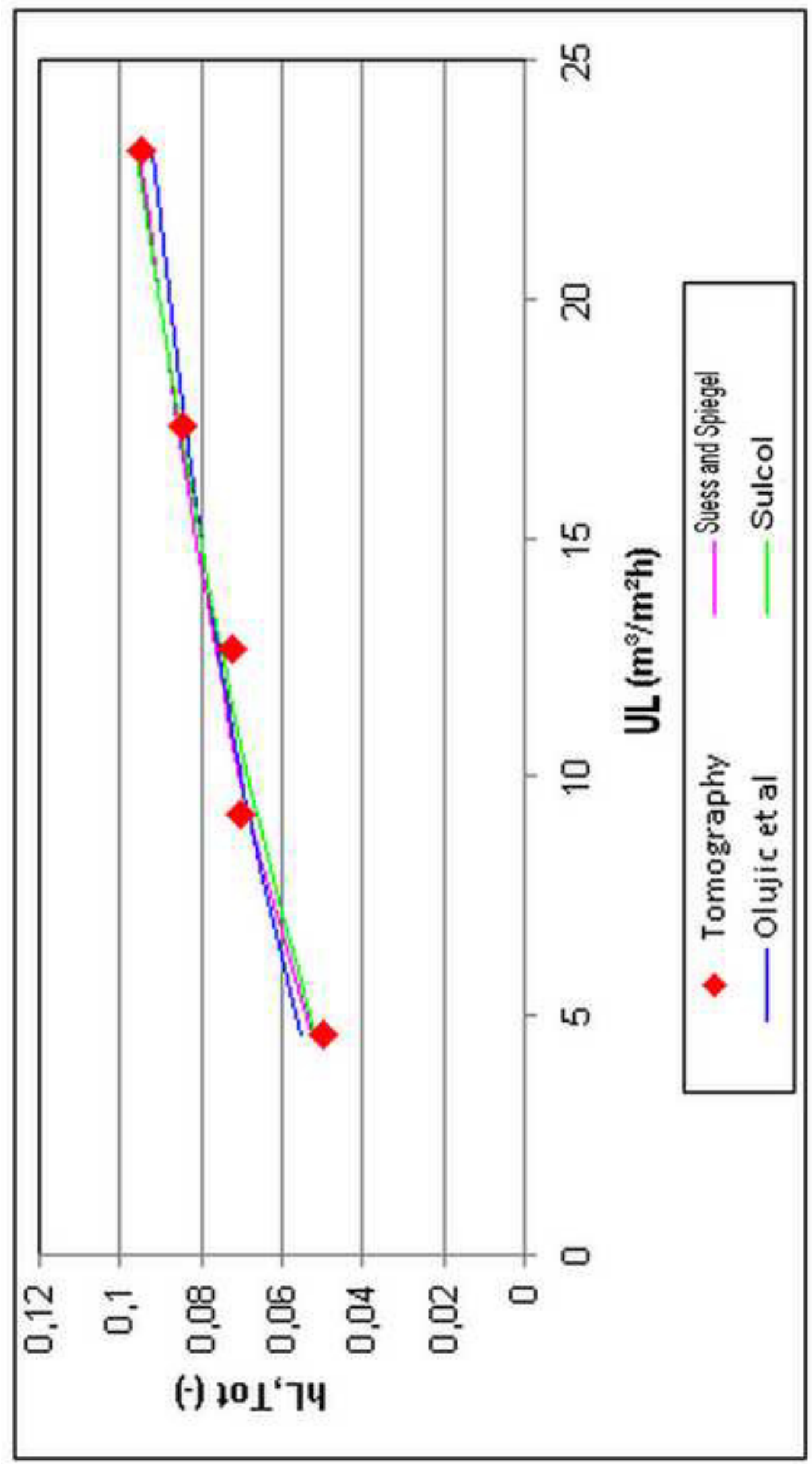

$\frac{\text { 는 }}{\text { 은 }}$ 


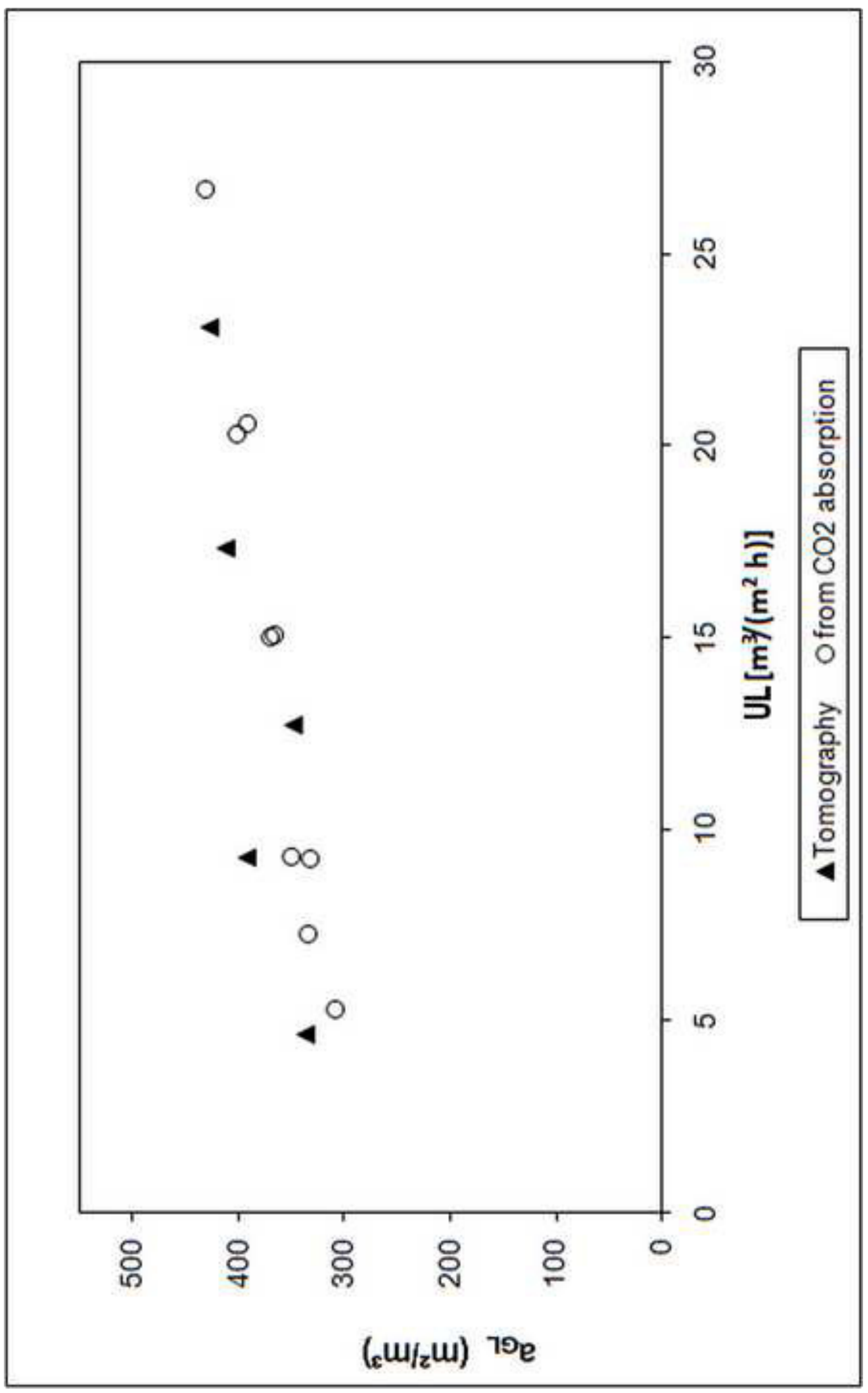




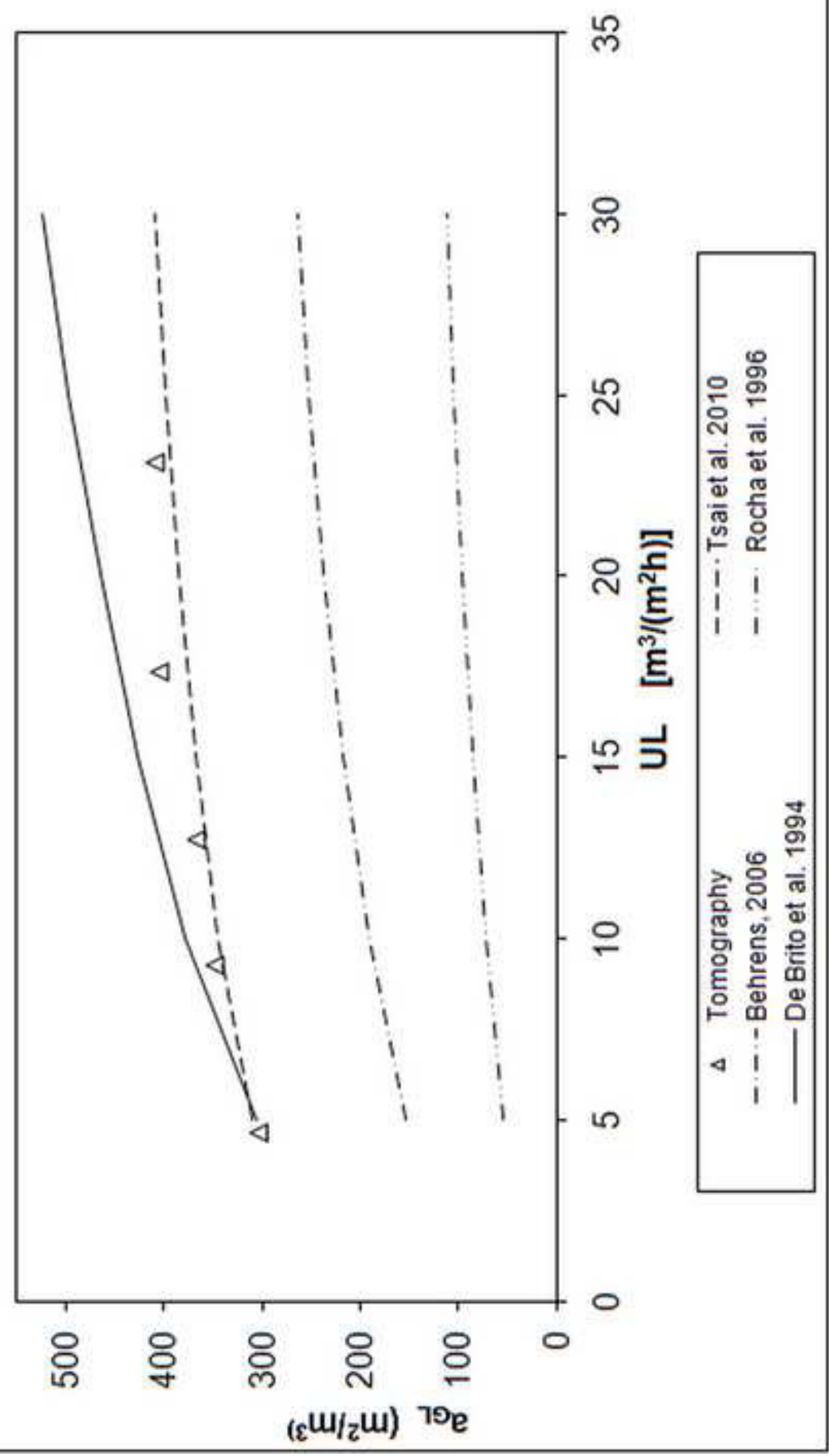

